\title{
Eimeria Species and Haemosporidia of Domestic Chickens and Guinea Fowls Sold at Selected Poultry Markets in Lagos, Nigeria
}

\author{
Emmanuel T. Idowu ${ }^{1}$, Oluwayomi O. Adeyemi ${ }^{*}$, Stephen C. Ezenwanne ${ }^{1}$, \\ Olubunmi A. Otubanjo ${ }^{1}$, Morakinyo B. Ajayi ${ }^{2}$ \\ ${ }^{I}$ Department of Zoology, University of Lagos, Lagos, Nigeria. \\ ${ }^{2}$ Microbiology Unit, Nigerian Institute of Medical Research (NIMR), Yaba, Lagos, \\ Nigeria.
}

*Correspondence should be addressed to Adeyemi O. Oluwatoyin: yadeyemi@unilag.edu.ng

Received 07 March 2019; Revised 31 March 2019; Accepted 12 April 2019

(C) 2019 Idowu et al. Licensee Pan African Jourmal of Life Sciences. This is an Open Access article distributed under the terms of the Creative commons Attribution License (https://creativecommons.org/licenses/BY/4.o), which permits unrestricted use, distribution, and reproduction in any medium, provided the original work is properly cited.

Introduction: Parasitic diseases are a major setback to sustainable poultry production. This study determined the occurrence of Eimeria species and haemosporidia among domestic chickens and helmeted guinea fowls in live-bird markets in Lagos State, Nigeria.

Methods: Blood samples and intestinal contents at three distinct segments of the gut were collected from 60 domestic chickens and guinea fowls each. Wet smears of intestinal contents were microscopically examined for oocysts typical of Eimeria species while thin films of blood were Giemsa-stained for the demonstration of protozoa.

Results: Results revealed that $19(31.7 \%)$ and $21(35 \%)$ chickens and guinea fowls were positive for $E i$ meria spp. infection respectively. There was no significant difference ( $\mathrm{P}>0.05)$ in Eimeria spp. infections between the chicken breeds nor between sexes of both birds. Oocysts of Eimeria were mostly recovered from the caeca and small intestines of the guinea fowls and chickens respectively. Domestic chickens were infected with three different haemoprotozoa: Plasmodium spp. (23.3\%), Leucocytozoon spp. (6.7\%) and Haemoproteus spp. (3.3\%); while Plasmodium spp. (15\%) and Haemoproteus spp. (3.3\%) were the only blood protozoa infecting guinea fowls. The infection rates of haemosporidia between the breeds of chickens and the sexes of both birds did not differ significantly $(\mathrm{P}>0.05)$.

Conclusion: Eimeria parasites and haemosporidia are prevalent among chickens and guinea fowls sold in Lagos State. To prevent severe economic losses in the future, appropriate control measures should be designed and implemented.

Keywords: Eimeria, haemosporidia, chicken, guinea fowl, Lagos State 


\section{1.o INTRODUCTION}

Poultry are birds such as chickens, turkeys, ducks, guinea fowls, pigeons, peasants, quails and ostriches domesticated for their nutritious meat and eggs [1]. Poultry farming makes substantial contribution to household and nationwide food security throughout the developing world [2]. In Africa, poultry meat is estimated to represent about $25 \%$ of all meat types, and in some areas accounts for $100 \%$ of the animal protein available [3]. In addition to their nutritional benefits, poultry serve as a colossal means of generating income and providing revenue [1]. The Nigerian poultry industry contributes about $15 \%$ to the country's Gross Domestic Profit (GDP) [4].

Diseases are however a major factor limiting poultry production globally. Various viral, bacterial and parasitic diseases are responsible for significant economic losses associated with high morbidity and mortality, and increased management costs $[1,5]$. Parasitic diseases rank high among these diseases which threaten the poultry industry [6]. Coccidiosis, an intestinal disease caused by the apicomplexan parasite, Eimeria costs the global poultry sector over US $\$ 3$ billion every year [7]. Presently, Eimeria parasites are recognized as one of the most important pathogens of intensively managed poultry. They negatively impact the overall gut health of their hosts; causing malabsorption, appetite loss, dehydration, reduced feed conversion efficiency, severe weight loss and death [8]. Also important among poultry are blood protozoa of the genera Plasmodium, Leucocytozoon and Haemoproteus. Although these haemoparasites are uncommon causes of severe morbidity and mortality, they have been implicated in occasional disease outbreaks that reduce bird fitness, feed consumption and conversion efficiencies [9].

Certain host, parasite, environmental and management factors determine the occurrence of these parasites and enhance their survival and spread among poultry. Indigenous poultry breeds are generally more resistant to local parasite strains when compared to their hybrid/exotic counterparts and may act as good reservoirs of infection [10]. The short, direct life-cycle and faeco-oral transmission route of Eimeria are reasons for its ubiquity in intensive poultry production where birds are usually densely stocked in confined units [8]. Haemoparasitic infections on the other hand are more common in free-ranging systems where birds are frequently exposed to bites of insect vectors [8].

Generally, live-bird markets (LBMs) in Nigeria - where variety of poultry species and products are sold to consumers for their consumption, for subsistence rearing and/or for rituals - are limited in infrastructure that help control the spread of Eimeria and haemosporidian parasites. Sanitary conditions at sales and slaughtering points are extremely poor. Proper waste disposal facilities, tap water or borehole systems, and easy-to-clean cages, floors, walls and drains are scarce [11]. Structures that ensure separation between birds and public and the quarantine of sick birds are also absent, putting poultry farms and free ranging birds in the environment at risk of infection [8].

There is dearth of information available on the prevalence of parasitic infections among poultry in Lagos, Nigeria. Such data is required to justify the need for control, to avert possible financial losses and ensure food security. This present study therefore aimed at determining the prevalence and intensity of Eimeria spp. and haemosporidian infections of domestic chickens and helmeted guinea fowls sold at selected LBMs in Lagos State.

\section{2.o METHODOLOGY}

\subsection{Study Area}

Lagos State is located in the mangrove region of the southwestern geopolitical zone of Nigeria, covering a land area of $3,577 \mathrm{~km} 2$, and about 41 meters above sea level. She has an average temperature of 31 degrees celcius and a relative humidity of $72 \%$. Lagos State is recognized as the commercial hub of Nigeria, with the highest Gross Domestic Profit (GDP) in Africa. This present study was carried out in LBMs at Oyingbo and Onipanu markets located within Lagos Island and Shomolu Local Government Areas (LGAs) of Lagos State respectively. Both LBMs are daily markets where urban and semi-urban consumers buy poultry and poultry products mainly obtained from distant or close commercial producers.

\subsection{Study Design}

This study lasted three months (January to March, 2017), with a total of 120 birds, comprising of 60 domestic chickens and 60 guinea fowls sampled at random at the LBMs. Only birds presented for slaughter and dressing were included in the study. The sexes (male or female) of the selected birds were recorded upon collection. Only the sampled chickens were categorized as exotic (i.e. specialized strain types such as layers, broilers or breeders) or local (i.e. indigenous chicken ecotypes) breed types.

\subsection{Sample Collection}

Fresh blood samples were collected from severed veins in the neck region of the selected birds into EDTA-coated bottles. Mucosal scrapings and contents of the small intestine, large intestine and caeca of each sampled bird 
were collected separately into sterile sample bottles. The samples were transported immediately to the laboratory for parasitological examination.

\subsection{Parasitological Examination}

Thin smears of blood were prepared and Giemsa-stained for microscopic examination of haemosporidia under $\times 100$ power objectives as described by [12].

The luminal contents and mucosal scrapings of the intestinal tract samples collected were concentrated by floatation method, using saturated $\mathrm{NaCl}(\mathrm{aq})$ solution and examined under the microscope at $\times 10$ and $\times 40$ power objectives for the presence of Eimeria oocysts [12]. The intensity of Eimeria infection in positive samples were categorized as unapparent (1-10 oocysts per field), low grade (11-20 oocysts per field) and severe (>20 oocysts per field) [13].

\subsection{RESULTS}

Eimeria spp. infection was encountered among 19(32\%) domestic chickens and 21(35\%) guinea fowls in this study (Table I). The infection rates between both sexes of chicken [male (38.5\%), female (26.5\%)] and guinea fowl [male (33.3\%), female (36.4\%)] were similar ( $\mathrm{P}>0.05)$. The was also no significant difference in Eimeria infection between the exotic (28.2\%) and local (38.1\%) breeds of chicken $(\mathrm{P}>0.05)$.

The prevalence rates of the haemosporidian infections occurring among the birds sampled in this study are presented in Table 1. Fourteen (23\%), 4(7\%) and 2(3\%) chickens were infected with Plasmodium, Leucocytozoon and Haemoproteus species respectively. Guinea fowls were only positive for blood protozoa of the genera Plasmodium (15\%) and Haemoproteus (3.3\%). The rate

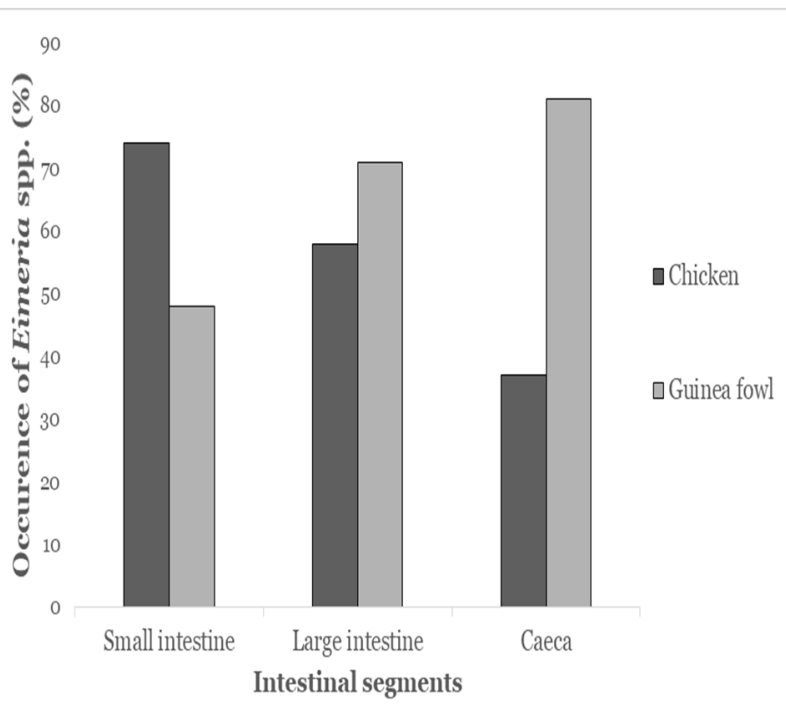

Figure 1: Eimeria spp. infections across selected segments of the gastro-intestinal tract of slaughtered chickens and guinea fowls

of Plasmodium spp. infection was significantly higher among local chickens (38.1\%) when compared to the exotic breeds $(15.4 \%)(\mathrm{P}<0.05)$. Also, more male $(26 \%)$ than female (6\%) guinea fowls were infected with Plasmodium spp. $(\mathrm{P}<0.05)$.

Table 2 presents the level of Eimeria spp. infection severity examined among infected poultry. Majority of birds had severe infections while 4(21.0\%) chickens and 2 (9.5\%) guinea fowls suffered from unapparent infections.

Oocysts of Eimeria spp. were mostly recovered from the small intestines of infected domestic chicken (74\%) and least in their caeca (37\%) (Figure 1). Infection with the protozoa was encountered least in the small intestines (48\%) of infected guinea fowls and highest in their caeca $(81 \%)$.

Table I: Prevalence of Eimeria spp. and haemosporidian infections among sampled poultry

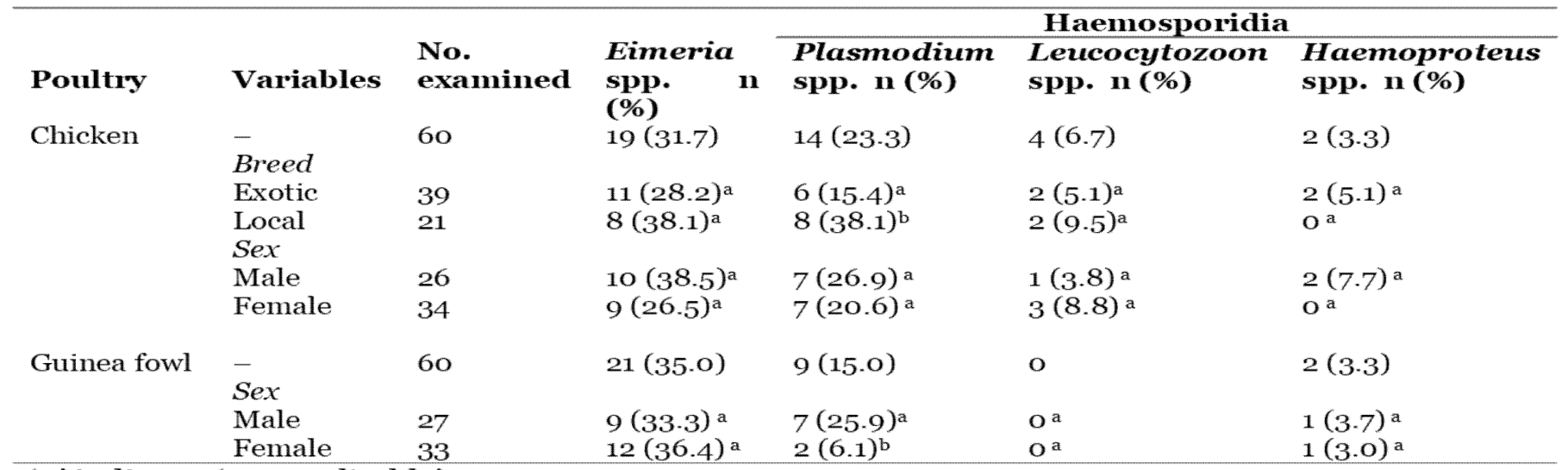

'-' indicates 'not applicable'

Values within a column marked by different letters are significantly different $(\mathbf{P}<0.05)$ 
Table 2: Severity of Eimeria spp. infections among slaughtered poultry

\begin{tabular}{lllll}
\hline Poultry & $\begin{array}{l}\text { No. } \\
\text { infected }\end{array}$ & $\begin{array}{l}\text { Unapparent } \\
\text { infections } \\
\text { n (\%) }\end{array}$ & $\begin{array}{l}\text { Low- } \\
\text { grade } \\
\text { infections } \\
\mathbf{n}(\%)\end{array}$ & $\begin{array}{l}\text { Severe } \\
\text { infections } \\
\mathbf{n}(\%)\end{array}$ \\
\hline Chicken & 19 & $4(21.0)$ & $1(5.3)$ & $14(73.7)$ \\
$\begin{array}{l}\text { Guinea } \\
\text { fowl }\end{array}$ & 21 & $2(9.5)$ & $3(14.3)$ & $16(76.2)$ \\
\hline
\end{tabular}

\section{4.o Discussion}

Protozoal diseases are common among domesticated birds, and some cause moderate to severe economic losses in both commercial and backyard production systems [8].

Eimeria spp. infection occurred at a prevalence rate of $32 \%$ among domestic chickens in this study. This finding is similar to those reported in in Ebonyi (33.6\%)[14], Kaduna (33.3\%) [13] and Enugu (35.5\%) [15] states of Nigeria. Surveys conducted in Ogun State $[16 ; 17]$, Ondo State [18], Abuja (FCT) [19; 20], and in Borno State [21] however revealed lower prevalence of $6.8 \%, 4 \%, 7.7 \%$, $14.6 \%, 25 \%$ and $12.6 \%$ respectively. Higher prevalence than what was recorded in this study were also reported among chickens in other parts of Nigeria [22; 23; 24]. These variations can be attributed to the different seasons in which these studies were conducted, the breed of chickens sampled, the farming systems and chicken management practices adopted in the respective study areas. The differences in prevalence rates may also reflect the quality of control in the various study areas.

The prevalence of Eimeria infection among local chickens (38.1\%) in this study was higher than that determined for exotic species. Although this finding was not statistically significant, it is similar to the results of Agbolade et al.[16] and Babatunde et al. [20], but different from those ofJatau et al. [13] and Lawal et al. [21] who reported higher prevalence of infection among exotic chicken breeds. Indigenous chicken strains are mostly managed extensively where the birds are allowed to scavenge for food in their environment. This free-ranging habit increases their risk of exposure to infective oocysts littered in the surroundings. Although, the local breeds of some domestic animals are resistant to endemic infectious diseases than the exotic strains [25], authors in another study carried out in Nigeria found no clear-cut difference in the susceptibility statuses of a Nigerian indigenous chicken line and broiler chickens experimentally infected with caecal isolates of Eimeria [26].

Majority of the domestic chickens positive for Eimeria oocysts in this study were severely infected. This finding is not in agreement with an ealier study where unapparent infections was observed to be most frequent among infected birds sampled at a live-bird market in Zaria, Kaduna [13] . Differences in the stocking densities of birds at both markets, the immunity of the sampled birds to Eimeria infection, the species or strains of Eimeria involved, and the effectiveness of the control tool(s) employed against coccidiosis at both study sites are plausible reasons for this discrepancy.

Eimeria are largely organ- and tissue- specific, and the degree of damage caused by a species is said to be dependent on its predilection site within its host's intestinal tract. Species which infect the lower regions of the gastro-intestinal tract are expected to be more virulent when compared to those infecting tissues in the upper regions [27]. In this study, oocysts were recovered mostly from the small intestines of infected chickens, followed by their large intestine and least from the caeca. It is therefore possible that the most prevalent species infecting the birds in this study are moderately pathogenic. Nonetheless, all seven species of Eimeria identified to affect chickens worldwide inflict economically significant damage on susceptible birds, regardless of their pathogenic status [28].

Little to no information exists on Eimeria spp. infection among guinea fowls, most studies have focused on the domestic chicken. The high percentage occurrence of Eimeria infections in the caeca of guinea fowls in thus study may however signify the presence of highly pathogenic species.

Three haemoprotozoan genera were encountered among chickens in this study: Plasmodium spp. (23.3\%), Leucocytozoon spp. (6.7\%) and Haemoproteus spp. (3.3\%). Previous studies in Nigeria have only reported the incidence of Plasmodium spp. and/or Haemoproteus spp. infections among domestic chickens [29; 30]. The availability of suitable ecology and ethology for insect vectors of Leucocytozoon spp. in the areas where the sampled birds were raised is a plausible reason for their occurrence in this study.

Plasmodium spp. (23.3\%) were the most prevalent blood protozoa infecting domestic chickens in this study. The infection rate of these blood parasites in a survey carried out in Kano State (21.1\%) [31] was similar to that reported in this study. However, studies by and in Borno (9.6\%) [32] and Sokoto (6\%) [33] states respectively revealed considerably lower infection rates, but higher prevalence rate in Imo (80\%) [30]. These differences can be attributed to varying climatic conditions in the areas where these investigations were carried out. 
Furthermore, avian malaria infections were remarkably higher among local chickens compared to exotic breeds. This finding agrees with the outcome of several other surveys carried out in Nigeria where exotic chickens were mostly found negative for avian malaria infection [30 33]. Although it was discovered otherwise in a study in Ogun State where the difference in infection rate between the breeds were not significant [25]. This finding may validate claim that indigenous breeds of domestic animals are less susceptible to local strains of parasites.

\subsection{Conclusion}

This study revealed that Eimeria parasites are prevalent among domestic chickens and helmeted guinea fowls sold at selected live-bird markets in Lagos State. Blood parasites belonging to three different apicomplexan genera-Plasmodium, Haemoproteus, and Leucocytozoon - were also encountered. The presence of these parasites, especially Eimeria spp. indicate potential financial losses and pose a threat to food security in Lagos State. Strict measures should be put in place immediately to control the spread of these infections among poultry in the State. Furthermore, research should be carried out in the future to ascertain the specific parasite species infecting these birds in the study area. Such data will inform rational and cost-effective control decisions.

\section{Acknowledgement}

The authors appreciate the poultry traders at Oyingbo and Onipanu markets for granting access to the birds sampled in this study.

\section{Authors ${ }^{6}$ Contribution}

ETI Concieved and designed the study, wrote the paper; OOA Collect data, contributed to analysis, wrote the paper; SCE Collected the data, performed analysis; OAO Concieved and designed the study, wrote the paper; MBA wrote paper. All authors approved the final version of the manuscript

\section{Declaration of Conflict of Interest}

The Authors declare that there is no conflict of interest.

\section{References}

1. Mohammed BR, Obeta SS. An Overview of the prevalence of avian coccidiosis in poultry production and its economic importance in Nigeria. Veterinary Research International. 2015; 3(3): 35-45.

2. Food and Agricultural Organization (FAO) of the United Nation, Rome. Quarterly Bulletin of Statistics. 2000; Vol. 1.
3. Permin A, Hansen JW. Epidemiology, diagnosis and control of poultry parasites, FAO Animal Health Manual. 1998; pp. 169.

4. Akintunde OK, Adeoti AI, Okoruwa VO, Omonona BT, Abu AO. Effect of disease management on profitability of chicken egg production in Southwest Nigeria. Asian Journal of Poultry Sciences. 2015; 9(1): 1-18.

5. Chapman HD. Coccidiosis in the turkey. Avian Pathology. 2008; 37(3): 205-223.

6. Adang KL, Asher R, Abba R. Gastro-intestinal Helminths of Domestic Chickens (Gallus gallus domestica) and Ducks (Anas platyrhynchos) slaughtered at Gombe Main Market, Gombe State, Nigeria. Asian Journal of Poultry Science. 2014; 8(2): 32-40.

7. Blake DP, Tomley FM. Securing poultry production from the ever-present Eimeria challenge. Trends in Parasitology. 2014; 30 (1): 14-20.

8. McDougald LR. Protozoal Infections; In: Saif YM, Fadly AM, Glosson JR, McDougald LR, Nolan LK, Swayne DE. (eds). Diseases of Poultry. 12th Edition. 9600 Garsington Road, Oxford QX4 2DQ. UK: Blackwell Publishing Ltd. 2008; pp. 1067-1117.

9. Momin A, Begum N, Dey AR, Paran S, Alam MZ. Prevalence of blood protozoa in poultry in Tangail, Bangladesh. Journal of Agriculture and Veterinary Science. 2014; 7(7): 5560.

10. Ikanni EI, Annatte AI. Advantages of keeping local chicken. Improving the performance of local chickens. Extension Bulletin No 92. Poultry series No 6. 2000; pp. 5-6.

11. FAO. Nigerian poultry sector. Assessment of the Nigerian poultry market chain to improve biosecurity. 2008; pp. 324.

12. FAO. Diagnostic Methods. Epidemiology, Diagnosis and Control of Poultry Parasites. FAO Animal Health Manuals. FAO, Rome 1996. 1998; pp. 73-118.

13. Jatau ID, Sulaiman NH, Musa IW, Lawal AI, Okubanjo OO, Isah I, Magaji Y. Prevalence of coccidian infection and preponderance Eimeria species in free range indigenous and intensively managed exotic chickens during hot-wet season in Zaria, Nigeria. Asian Journal of Poultry Science. 2012; 6:79-88.

14. Ngele KK. Prevalence of Eimeria species on exotic chickens reared in Afikpo Metropolis, Ebonyi State, Nigeria. FUNAI Journal of Science and Technology. 2017; 3(2): 67-81.

15. Nnadi PA, George SO. A cross-sectional survey on parasites of chickens in selected villages in the subhumid zones of South-Eastern Nigeria. Journal of Parasitology Research. 2010; pp. 1-6.

16. Agbolade OM, Arosoye AS, Akajiugo EC, Akinyemi HA, Owolowo AM, Ariba O, Jonathan KA. Gastrointestinal parasites of domestic fowls from Ijebu-North, Southwestern 
Idowu et al Pan African Journal of Life Sciences (2019): 67-72 Nigeria. Basic Research Journal of Agricultural Science and Review. 2014; 3(7): 60-64.

17. Kolade OE, Agbolade OM. Intestinal parasites of local and exotic domestic fowls in Owoyele, Yewa North, Ogun State, Nigeria. Agriculture and Soil Sciences (LRJASS). 2014; 1 (6): 82-85.

18. Afolabi OJ, Simon-Oke IA, Olasukanmi AO. Intestinal parasites of domestic chicken (Gallus gallus domesticus) in Akure, Nigeria. Journal of Biomedicine. 2016; 1(4): 1-4.

19. Jegede OC, Asadu JA, Opara M, Obeta SS, Olayemi D. Gastrointestinal parasitism in local and exotic breeds of chickens reared in Gwagwalada, Guinea Savannah Zone of Nigeria. Sokoto Journal of Veterinary Sciences. 2015; 13(3): 2530.

20. Babatunde SM, Mohammed BR, Simon MK, Agbede RIS. Coccidial infection in free-range and intensively managed chickens in Gwagwalada Area council, Abuja-Nigeria, SubSaharan Africa. Alexandria Journal of Veterinary Sciences. 2016; 51(2): 183-188.

21. Lawal JR, Gulani IA, Ali AM, Bello AM, Abadam FA, Mustapha M, Dauda J, Adamu L, Biu AA. Dry season prevalence of avian coccidian infection in domesticated chickens (Gallus gallus domesticus) in Jere Council, Bornu State, Nigeria. Journal of Animal Science and Veterinary Medicine. 2016; 1:67-73.

22. Adang LK, Isah Z. Prevalence of Eimeria species in local breed chickens in Gombe metropolis, Gombe State, Nigeria. International Journal of Biological and Chemical Science. 2016; 10(6): 2667-2672.

23. Agishi G, Luga II, Rabo JS. Prevalence of coccidiosis and Eimeria species in Layers and Broilers at Slaughter Houses in Makurdi, Benue state. The International Journal of Engineering and Science (IJES). 2016; 5(2): 8-11.

24. Rufai MA, Jato AO. Assessing the prevalence of gastrointestinal tract parasites of poultry and their environmental risk factors in poultry in Iwo, Osun State, Nigeria. Ife Journal of Science. 2017; 19(1): 7-13.

25. Chiejina SN, Behnke JM, Nnadi PA, Ngongeh LA, Musongong GA. The responses of two ecotypes of Nigerian
West African Dwarf goat to experimental infections with Trypanosoma brucei and Haemonchus contortus. Small Ruminant Research. 2009; 85(2-3): 91-98.

26. Ngongeh LA, Onyeabor A, Nzenwata E, Samson GK. Comparative Response of the Nigerian Indigenous and Broiler Chickens to a Field Caecal Isolate of Eimeria Oocysts. Journal of Pathogens. 2017; pp. 1-9.

27. Pakandl M. Coccidia of rabbit: a review. Folia Parasitologica, 2009; 56(3): 153-166.

28. McDougald LR. Intestinal protozoa important to poultry. Poultry Science. 1998; 77:1156-1158.

29. Lawal JR, Bello AM, Balami SY, Dauda J, Malgwi KD, Ezema KU, Kasim M, Biu AA. Prevalence of haemoparasites in village chickens (Gallus gallus domesticus) slaughtered at poultry markets in Maiduguri, Northeastern Nigeria. Journal of Animal Science and Veterinary Medicine, 2016; 1:3945 .

30. Opara MN, Okereke R, Olayemi D, Jegede C. Haemoparasitism of local and exotic chickens reared in the tropical rainforest zone of Owerri, Nigeria. Alexandria Journal of Veterinary Sciences. 2016; 51(1): 84-89.

31. Karamba KI, Kawo AH, Dabo NT, Mukhtar MD. A survey of avian malaria parasite in Kano State, Northern Nigeria. International Journal for Biotechnological and Molecular Biology Research. 2012; 3(1): 8-14.

32. Igbokwe IO, Hassan SU, Faive ZT, Iliya Y, Dagare MJ, Rabo JS, Mohammed A, Igbokwe NA. Effect of Plasmodium species infections on packed cell volume of domestic chickens and helmeted guinea fowls in North-eastern Nigeria. Animal Research International. 2008; 5(3): 892-895.

33. Usman M, Fabiyi JP, Mohammed AA, Mera UM, Mahmuda A, Alayande MO, Lawal MD, Danmaigoro A. Ectoparasites and haemoparasites of chickens in Sokoto, Northwestern Nigeria. Scientific Journal of Zoology. 2012; 1(3): 7478. 